\title{
Pumping-induced leakage in a bounded aquifer: An example of a scale-invariant phenomenon
}

\author{
James J. Butler Jr. and Ming-shu Tsou ${ }^{1}$ \\ Kansas Geological Survey, University of Kansas, Lawrence, Kansas, USA \\ Received 28 May 2002; revised 25 September 2003; accepted 2 October 2003; published 5 December 2003
}

[1] A new approach is presented for calculation of the volume of pumping-induced leakage entering an aquifer as a function of time. This approach simplifies the total leakage calculation by extending analytical-based methods developed for infinite systems to bounded aquifers of any size. The simplification is possible because of the relationship between drawdown and leakage in aquifers laterally bounded by impermeable formations. This relationship produces a scale-invariant total leakage; i.e., the volume of leakage as a function of time does not change with the size of the aquifer or with the location of the pumping well. Two examples and image well theory are used to demonstrate and prove, respectively, the generality of this interesting phenomenon. INDEX TERMS: 1829 Hydrology: Groundwater hydrology; 1894 Hydrology: Instruments and techniques; KEYWORDS: pumping-induced leakage, scale-invariant measurements, total leakage

Citation: Butler, J. J., Jr., and M.-S. Tsou, Pumping-induced leakage in a bounded aquifer: An example of a scale-invariant phenomenon, Water Resour. Res., 39(12), 1344, doi:10.1029/2002WR001484, 2003.

\section{Introduction}

[2] Pumping-induced flow through layers of relatively low permeability (leakage) is a common hydrologic mechanism of importance for a wide range of practical applications (Figure 1). Leakage is often a significant component of the hydrologic budget of an aquifer undergoing development. If a stream overlies the confining bed, leakage may also be a critical factor in water rights and minimum-streamflow considerations. In many situations, pumping-induced leakage can be the mechanism by which contaminants move into an aquifer used for drinking-water supplies. In addition, leakage may often be the primary determinant of well yields.

[3] The quantification of the volume of pumping-induced leakage entering an aquifer (henceforth, total leakage) as a function of time is necessary for many such applications. In aquifers that resemble the hypothetical infinite systems of the well hydraulics literature, analytical expressions [e.g., Hantush and Jacob, 1955; Hantush, 1960; Neuman and Witherspoon, 1969; Butler et al., 2001] can be integrated through space to estimate the total leakage produced by pumping at individual wells. In less-ideal systems, numerical models are used to determine total leakage through a summation over the active cells [e.g., Anderson and Woessner, 1992]. Obviously, in either case, the computation becomes trivial once steady state conditions are achieved.

[4] A new approach for calculation of total leakage in aquifers that are laterally bounded by impermeable formations is introduced here. The approach simplifies the calculation by extending analytical-based methods developed for infinite systems to bounded aquifers of any size. The simplification is possible because of the relationship

\footnotetext{
${ }^{1}$ Now at HydroGeoLogic, Inc., Austin, Texas, USA.
}

between drawdown and leakage in aquifers bounded by impermeable formations. This relationship produces a scaleinvariant total leakage, an interesting hydrologic phenomenon that has not previously been reported.

[5] The purpose of this note is to present this new analytical-based approach for the calculation of total leakage, and to demonstrate that total leakage does not change with the size of the aquifer or the distance of the pumping well from a no-flow boundary. The note begins with a brief derivation of analytical expressions for total leakage in laterally infinite aquifers. The derivation will be presented in Laplace space to more clearly emphasize the points of interest here. Two examples are then used to demonstrate the scale invariance of total leakage in bounded systems. In both cases, image well theory [e.g., Ferris et al., 1962] and the previously derived analytical expressions are utilized to prove the generality of the scale invariance. The note concludes with a brief summary of the major points.

\section{Analytical Calculation of Total Leakage}

[6] A number of analytical solutions have been proposed for transient flow to a pumping well in a semiconfined aquifer. One of the earliest reported solutions is that of Hantush and Jacob [1955] in which the storage properties of the confining bed are neglected and the head in the adjacent aquifer is assumed to be constant (Figure 1). In that case, the expression for drawdown in a laterally infinite semiconfined aquifer given as equation (6) of Hantush and Jacob [1955] can be written in dimensionless form in Laplace space as:

$$
\overline{\mathrm{s}}_{\mathrm{d}}=\frac{\mathrm{K}_{0}\left(\lambda r_{\mathrm{d}}\right)}{\mathrm{p}}
$$

where $\overline{\mathrm{s}}_{\mathrm{d}}$ is dimensionless drawdown, equal to $(2 \pi \mathrm{T} \overline{\mathrm{s}}) / \mathrm{Q} ; \overline{\mathrm{s}}$ is Laplace space drawdown in pumped aquifer, equal to 


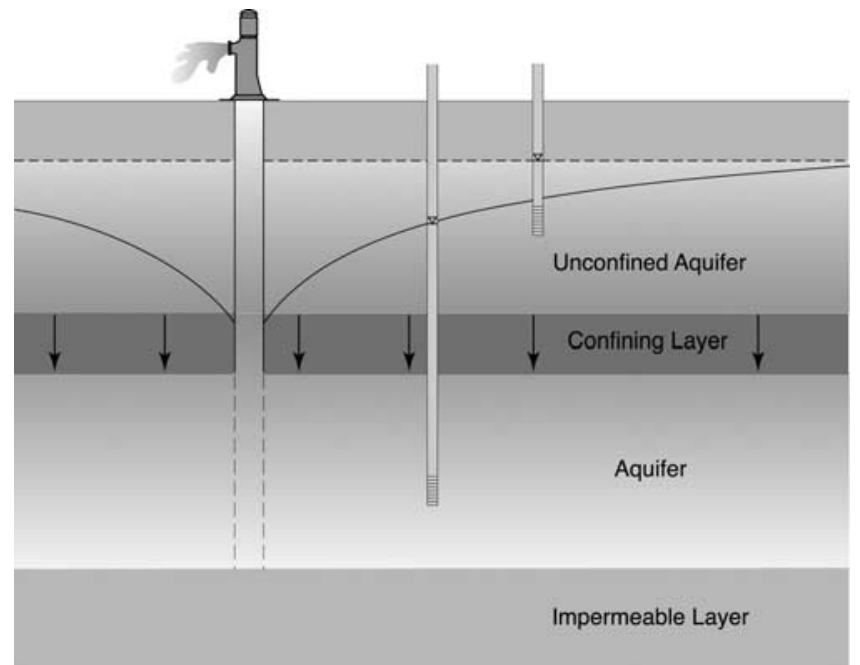

Figure 1. Cross-sectional view of a hypothetical semiconfined aquifer and adjacent units. Pumping in the semiconfined aquifer induces vertical flow across the confining layer; head in the unconfined aquifer is unaffected by pumping.

$\int_{0}^{\infty}\left(\mathrm{e}^{-\mathrm{pt}} \mathrm{s}\right) \mathrm{dt}$ (an overbar will be used throughout this article to designate a Laplace space variable); $\mathrm{s}$ is drawdown in pumped aquifer; $\mathrm{T}$ is transmissivity of aquifer, equal to $\mathrm{Kb}$; $\mathrm{K}$ is hydraulic conductivity of aquifer; $\mathrm{b}$ is aquifer thickness; $\mathrm{Q}$ is pumping rate; $\mathrm{K}_{0}$ is modified Bessel function of the second kind of order zero; $\mathrm{p}$ is Laplacetransform variable; $r_{d}=r / b ; r$ is radial distance from the pumping well; $\lambda=\left(\frac{1}{B_{d}^{2}}+p\right)^{1 / 2} ; B_{d}$ is dimensionless leakage factor, equal to $\left(\mathrm{Kb}^{\prime} / \mathrm{K}^{\prime} \mathrm{b}\right)^{1 / 2} ; \mathrm{b}^{\prime}$ is thickness of confining layer; and $\mathrm{K}^{\prime}$ is hydraulic conductivity of confining layer. The details of the derivations for equation (1) and all other equations presented in this section are given by Butler [2003].

[7] The leakage through a ring of infinitely small width centered on the pumping well can be written in dimensionless form in Laplace space as:

$$
\overline{\mathrm{q}}_{\mathrm{zd}}=\left(\mathrm{r}_{\mathrm{d}} \mathrm{dr}_{\mathrm{d}} \overline{\mathrm{s}}_{\mathrm{d}}\right) / \mathrm{B}_{\mathrm{d}}^{2}
$$

where $\mathrm{q}_{\mathrm{zd}}=$ dimensionless leakage $\left(\mathrm{q}_{\mathrm{z}} / \mathrm{Q}\right)$, and $\mathrm{q}_{\mathrm{z}}=$ pumping-induced leakage.

[8] An expression for total leakage can be obtained by integrating equation (2) from $r_{d}=0$ to $\infty$ and substituting equation (1) for $\overline{\mathrm{s}}_{\mathrm{d}}$ :

$$
\overline{\mathrm{Q}}_{\mathrm{zd}_{\mathrm{inf}_{\mathrm{HJ}}}}=\frac{1}{\mathrm{~B}_{\mathrm{d}}^{2}} \int_{0}^{\infty} \mathrm{r}_{\mathrm{d}} \overline{\mathrm{s}}_{\mathrm{d}} \mathrm{dr} \mathrm{r}_{\mathrm{d}}=\frac{1}{\mathrm{pB}} \int_{\mathrm{d}}^{2} \mathrm{r}_{\mathrm{d}} \mathrm{K}_{0}\left(\lambda r_{\mathrm{d}}\right) \mathrm{dr}_{\mathrm{d}}
$$

where $\mathrm{Q}_{\mathrm{zd}_{\mathrm{inf}_{\mathrm{HI}}}}$ is dimensionless total leakage $\left(\mathrm{Q}_{\mathrm{Z}} / \mathrm{Q}\right)$ in a semiconfined infinite aquifer obtained using the Hantush and Jacob [1955] model and $\mathrm{Q}_{\mathrm{z}}$ is pumping-induced total leakage. By definition, $\mathrm{Q}_{\mathrm{zd}_{\text {inf }_{\mathrm{H}}}}$ must vary between zero (negligible amount of water moving across the confining bed) and one (the rate of water movement across the confining bed equals the pumping rate (Q), steady state leakage). In the remainder of this article the Stehfest [1970] algorithm will be used to numerically invert equation (3) and the other Laplace space expressions, as is the common practice in the well-hydraulics literature [e.g., Moench and Ogata, 1984]

[9] Figure 2a is a plot of $\mathrm{Q}_{\mathrm{zd}_{\mathrm{inf}_{\mathrm{f}}}}$ versus dimensionless time $\left(t_{d}=\mathrm{Tt} / \mathrm{Sb}^{2}, \mathrm{~S}=\right.$ storage coefficient of aquifer) for a range of values of the dimensionless leakage parameter $\left(B_{d}\right)$. Although $\mathrm{Q}_{\mathrm{zd}_{\mathrm{in}_{\mathrm{H}}}}$ must eventually reach one with continued pumping, the dependence on $\mathrm{B}_{\mathrm{d}}$ can produce large differences in total leakage prior to the attainment of steady state conditions.

[10] Analytical expressions for total leakage can also be obtained by relaxing some of the more restrictive assumptions of the preceding development. For example, if a nonnegligible storage coefficient $\left(\mathrm{S}^{\prime}\right)$ is assumed for the confining layer, an expression for total leakage can be obtained for the solution of Hantush [1960] by following
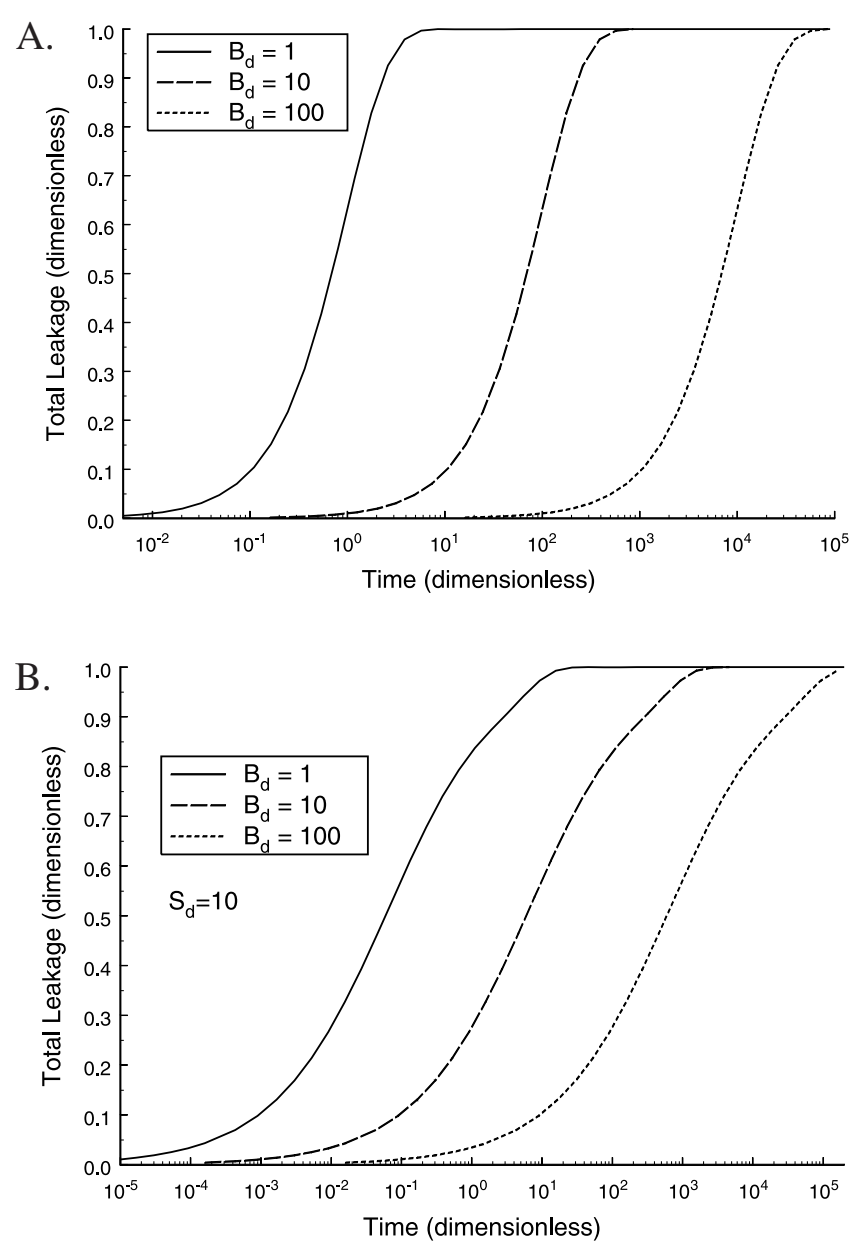

Figure 2. (a) Dimensionless total leakage $\left(\mathrm{Q}_{\mathrm{z}} / \mathrm{Q}\right)$ versus dimensionless time $\left(\mathrm{Tt} / \mathrm{Sb}^{2}\right)$ plot calculated with equation (3) using the Hantush and Jacob [1955] conceptualization of a semiconfined aquifer of infinite extent. (b) Dimensionless total leakage versus dimensionless time plot calculated with equation (4) using the Hantush [1960] conceptualization of a semiconfined aquifer of infinite extent $\left(\mathrm{B}_{\mathrm{d}}=\left(\mathrm{Kb}^{\prime} /\right.\right.$ $\left.\mathrm{K}^{\prime} \mathrm{b}\right)^{1 / 2} ; \mathrm{S}_{\mathrm{d}}=\mathrm{S}^{\prime} / \mathrm{S}$; in porous semiconfined aquifer systems, $B_{d}$ will often be between 1 and 100 , and $S_{d}$ will be greater than 1 . 
A.

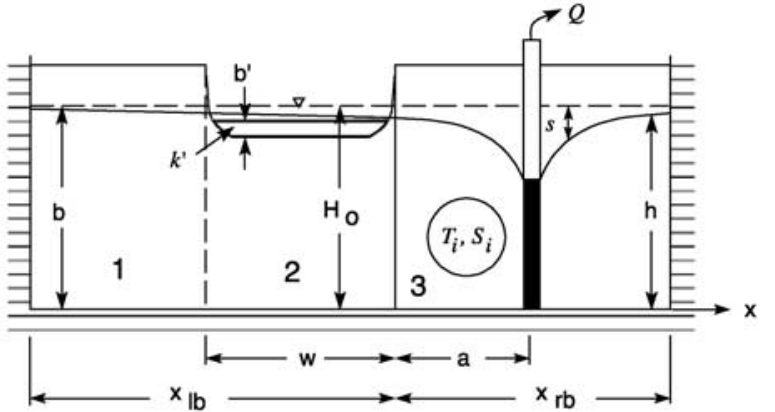

B.

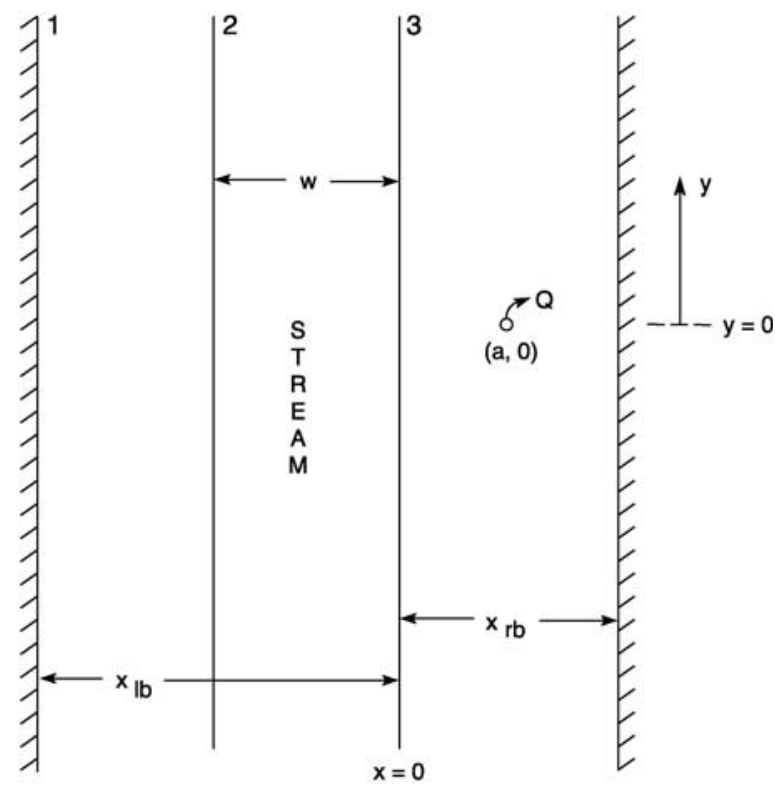

Figure 3. (a) Cross-sectional and (b) areal views of a hypothetical stream-aquifer system (stream depletion in this configuration consists of vertical leakage across the lowpermeability streambed; after Butler et al. [2001]).

the same approach as used for the Hantush and Jacob [1955] solution:

$$
\overline{\mathrm{Q}}_{\mathrm{zd}_{\mathrm{inf}}}=\frac{1}{\mathrm{p} \Gamma^{2}} \int_{0}^{\infty} \mathrm{r}_{\mathrm{d}} \mathrm{K}_{0}\left(\gamma \mathrm{r}_{\mathrm{d}}\right) \mathrm{dr}_{\mathrm{d}}
$$

where

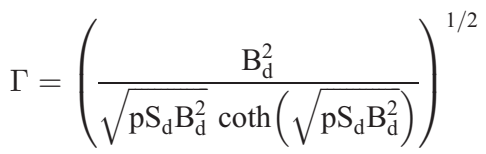

if confining bed abuts a constant-head aquifer,

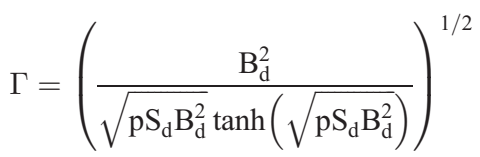

if confining bed abuts an impermeable formation,

$$
\gamma=\left(\frac{1}{\Gamma^{2}}+\mathrm{p}\right)^{1 / 2}
$$

coth is hyperbolic cotangent function, tanh is hyperbolic tangent function, $\mathrm{Q}_{\mathrm{zd}_{\text {inf }_{\mathrm{H}}}}$ is dimensionless total leakage in a semiconfined infinite aquifer obtained using the Hantush [1960] model, and $\mathrm{S}_{\mathrm{d}}=\mathrm{S}^{\prime} / \mathrm{S}$. Figure $2 \mathrm{~b}$ is a plot of $\mathrm{Q}_{\mathrm{zd}_{\mathrm{inf}}}$ versus dimensionless time generated using equation (4) for the case of a constant head in the unpumped aquifer. The inclusion of storage in the confining layer significantly alters the form of the plots of total leakage. If the head in the nonpumped aquifer is affected by pumping, the solution of Neuman and Witherspoon [1969] can be used to obtain an expression for total leakage. Although not given here, that expression has the same general form as equations (3) and (4), albeit with more parameters.

[11] Analogous expressions can also be obtained for the case of a stream and aquifer separated by a thin layer (streambed) of low permeability. Figure 3 is an areal and cross-sectional view of a stream-aquifer system in which pumping induces flow from the stream through the lowpermeability streambed. In this case, the total pumpinginduced leakage from the stream is termed stream depletion. For a streambed of negligible storage and a stream of shallow penetration and constant head, the leakage through an infinitely thin strip of the streambed that extends the full width of the stream can be written in dimensionless form in Laplace space using the solution of Butler et al. [2001]:

$$
\overline{\mathrm{q}}_{\mathrm{zd}}=\frac{1}{\mathrm{~B}_{\mathrm{d}_{\mathrm{sa}}}^{2}}\left(\int_{-1}^{0} \overline{\mathrm{s}}_{\mathrm{d}} \mathrm{dx}_{\mathrm{d}}\right) \mathrm{dy_{ \textrm {d } }}
$$

where $\overline{\mathrm{s}}_{\mathrm{d}}$ is dimensionless drawdown underneath the stream, equal to $\mathrm{T} \overline{\mathrm{s}} / \mathrm{Q} ; \mathrm{B}_{\mathrm{d}_{\mathrm{sa}}}$ is dimensionless leakage parameter for stream-aquifer system, equal to $\left(\mathrm{b}^{\prime} \mathrm{T} / \mathrm{K}^{\prime} \mathrm{w}^{2}\right)^{1 / 2} ; \mathrm{w}$ is stream width; $\mathrm{x}_{\mathrm{d}}=\mathrm{x} / \mathrm{w}$; and $\mathrm{y}_{\mathrm{d}}=\mathrm{y} / \mathrm{w}$.

[12] An expression for total leakage (stream depletion) can be obtained by integrating equation (5) in the y direction from $-\infty$ to $+\infty$ [Butler et al., 2001]:

$$
\overline{\mathrm{Q}}_{\mathrm{zd}_{\mathrm{inf}_{\mathrm{BZT}}}}=\frac{1}{\mathrm{~B}_{\mathrm{d}_{\mathrm{sa}}}^{2}} \int_{-\infty}^{+\infty} \int_{-1}^{0} \overline{\mathrm{s}}_{\mathrm{d}} \mathrm{dx}_{\mathrm{d}} \mathrm{dy} \mathrm{d}_{\mathrm{d}}
$$

where $\mathrm{Q}_{\mathrm{zd}_{\text {inf }} \mathrm{f}_{\mathrm{BZT}}}$ is dimensionless stream depletion in an infinite stream-aquifer system obtained using the Butler et al. [2001] model. Note that the notation of Butler et al. [2001] has been modified here to be consistent with the notation of this article.

\section{Scale Invariance of Total Leakage}

[13] The expressions presented in the preceding section were derived for a semiconfined aquifer of infinite lateral extent (equations (3) and (4)) and a stream-aquifer system of infinite length (equation (6)). In many cases, however, the aquifer is truncated by impermeable boundaries that are close enough to the pumping well to affect drawdown. The issue of how total leakage changes in such situations is one of considerable practical importance. Fortunately, the scale invariance of total leakage greatly simplifies the required calculations. This scale invariance is defined and demonstrated in the following paragraphs. 
A.

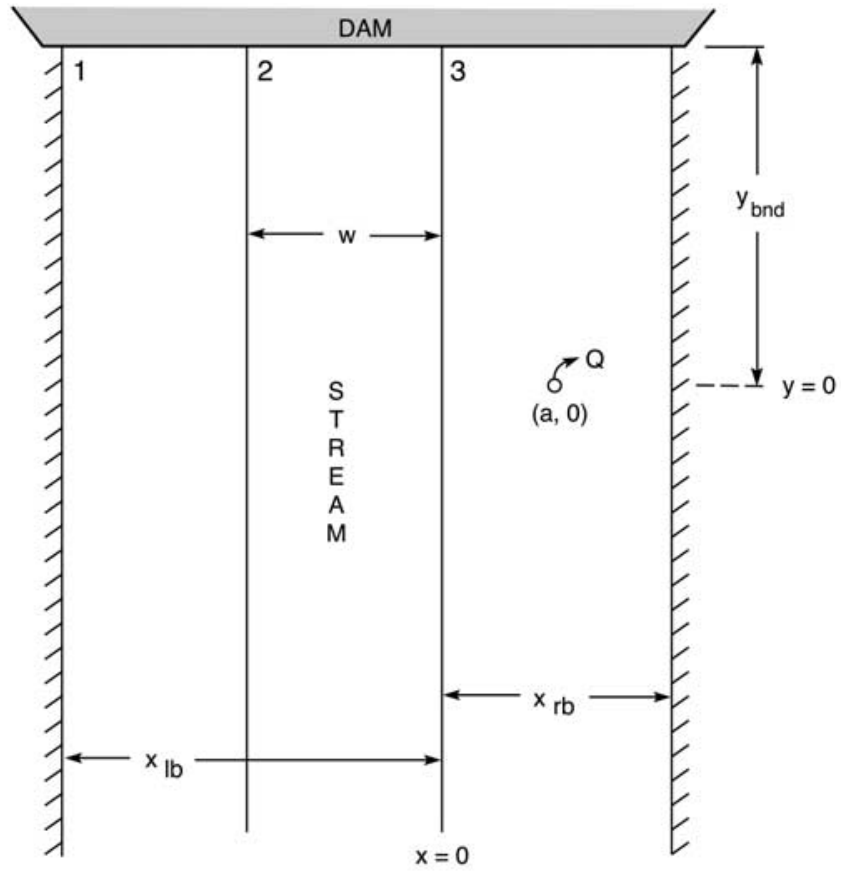

B

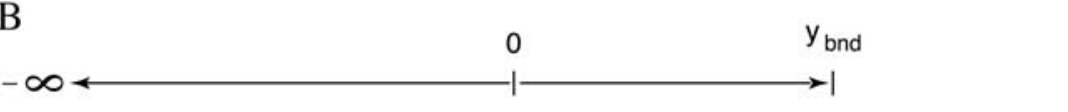

Pumping Well Coordinate System

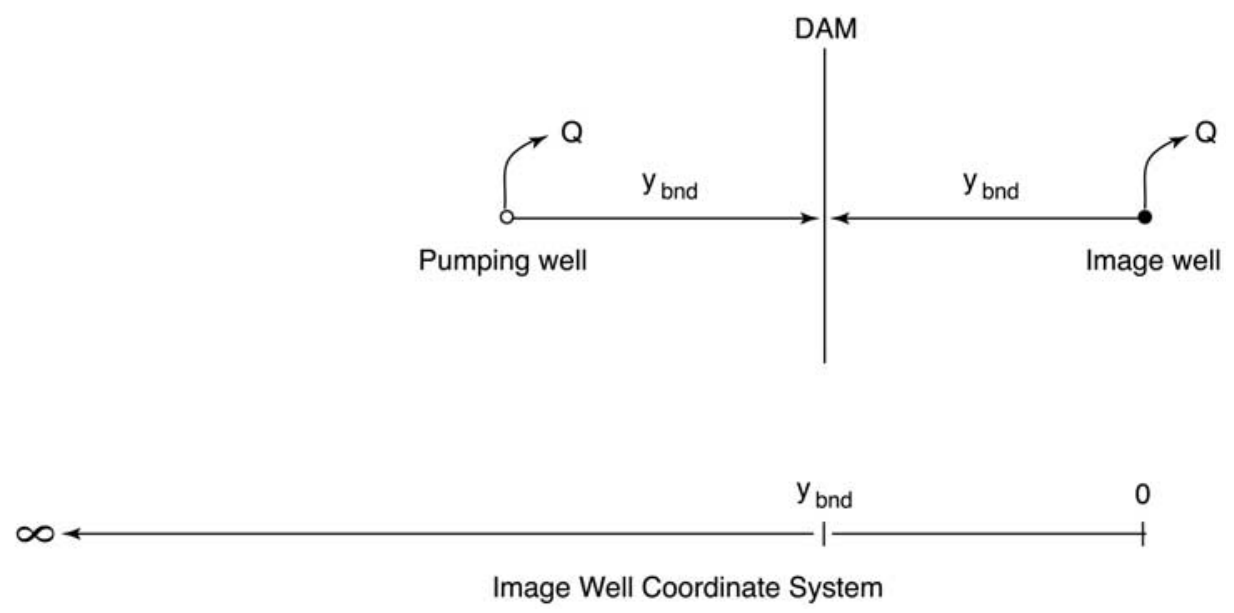

Figure 4. (a) Areal view of hypothetical stream-aquifer system truncated by a dam. (b) Image well representation of the impermeable boundary created by the dam (rotated $90^{\circ}$ with respect to Figure 4a).

[14] The term scale-invariant leakage is used here to designate the condition when total leakage does not change with the size of the aquifer or the distance of the pumping well from a lateral no-flow boundary. Two examples are given to demonstrate this phenomenon.

[15] A simple example of scale-invariant leakage can be observed in the truncated stream-aquifer system of Figure 4a. In this case, pumping-induced drawdown and stream depletion can be calculated with the solution of Butler et al. [2001] using a single image well to model the no-flow boundary in the y direction (Figure $4 b$ ). The drawdown and stream-depletion plots for a stream-aquifer system of infinite length and the truncated system of Figure 4a are presented in Figures 5a and 5b. Although drawdown varies with the distance from the pumping well to the no-flow boundary in the y direction (Figure 5a), stream depletion does not (Figure $5 b$ ). In all cases, the stream-depletion curves for the infinite and truncated systems coincide, despite the differences in drawdown. Additional calculations have shown that this coincidence of stream-depletion curves occurs regardless of the distance from the pumping well to the boundary in the y direction.

[16] The universality of this scale invariance for systems similar to that in Figure 4a can be proven using image well theory. In the case of a single impermeable boundary perpendicular to the stream (Figure 4b), stream depletion is the summation of the leakage produced by the pumping well and that produced by the single image well. The 

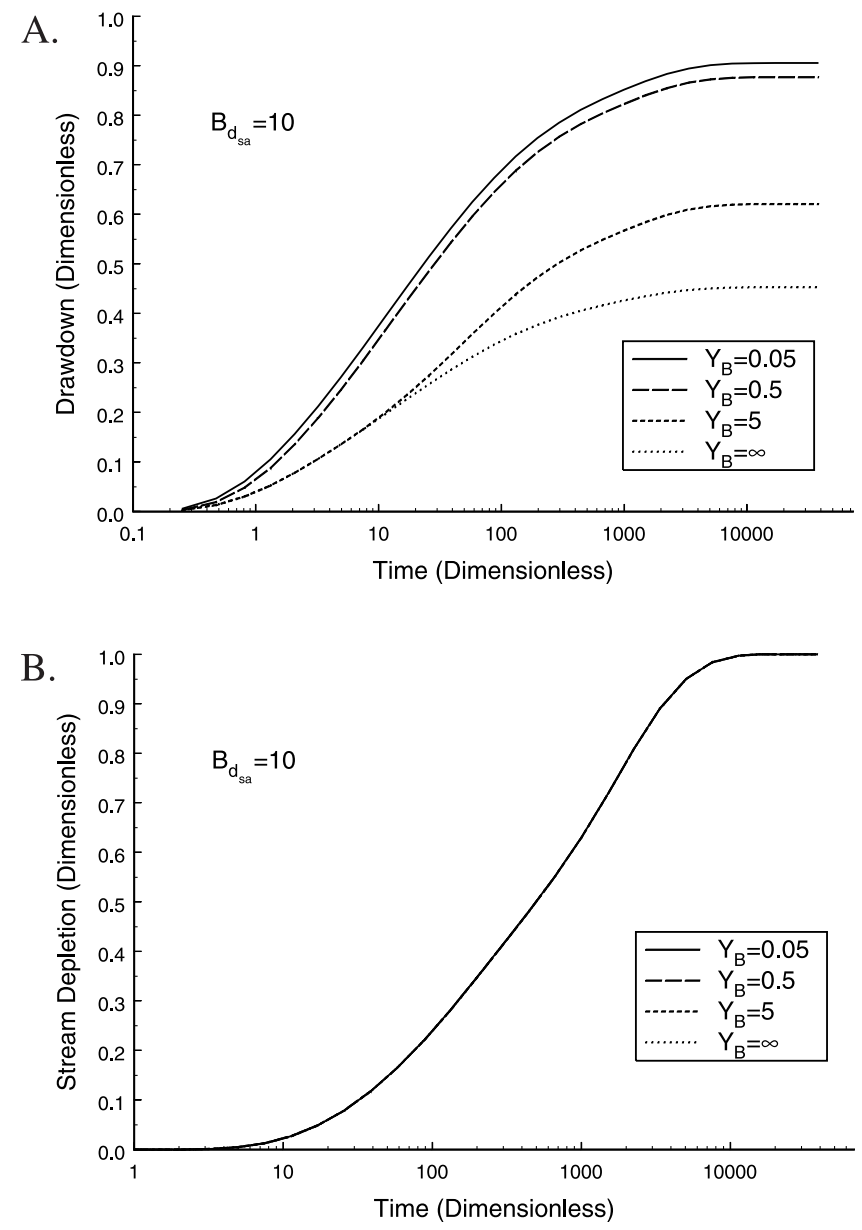

Figure 5. (a) Dimensionless drawdown (sT/Q) versus dimensionless time $\left(\mathrm{Tt} / \mathrm{Sw}^{2}\right)$ plot for truncated (Figure $4 \mathrm{a}$ ) and infinite (Figure 3) stream-aquifer systems. (b) Dimensionless stream depletion $\left(\mathrm{Q}_{\mathrm{Z}} / \mathrm{Q}\right)$ versus dimensionless time plot for these same systems $\left(\mathrm{B}_{\mathrm{dan}_{\mathrm{sa}}}=\left(\mathrm{b}^{\prime} \mathrm{T} / \mathrm{K}^{\prime} \mathrm{w}^{2}\right)^{1 / 2} ; \mathrm{Y}_{\mathrm{B}}=\mathrm{y}_{\mathrm{bnd}} / \mathrm{w}\right.$; pumping and observation wells located at $(5,0)$ and $(3.5,0)$, respectively).

component of stream depletion produced by each well is calculated by integrating the analytical expression for leakage (equation (5)) over the truncated aquifer. The component produced by the pumping well is

$$
\overline{\mathrm{Q}}_{z \mathrm{~d}_{1}}=\frac{1}{\mathrm{~B}_{\mathrm{d}_{s a}}^{2}} \int_{-\infty}^{\mathrm{Y}_{\mathrm{b}}} \int_{-1}^{0} \overline{\mathrm{s}}_{\mathrm{d}} \mathrm{dx}_{\mathrm{d}} \mathrm{dy}_{\mathrm{d}}
$$

where $Y_{b}$ equals $y_{b n d} / w$, and the origin of the coordinate system is at the pumping well.

[17] The component produced by the image well is

$$
\overline{\mathrm{Q}}_{\mathrm{zd}_{2}}=\frac{1}{\mathrm{~B}_{\mathrm{s}_{s}}^{2}} \int_{\mathrm{Y}_{\mathrm{b}}}^{+\infty} \int_{-1}^{0} \overline{\mathrm{s}}_{\mathrm{d}} \mathrm{dx}_{\mathrm{d}} \mathrm{dy}_{\mathrm{d}}
$$

where the origin of the coordinate system is at the image well. The summation of these two terms is

$$
\overline{\mathrm{Q}}_{\mathrm{z}_{1}}+\overline{\mathrm{Q}}_{\mathrm{zd}_{2}}=\frac{1}{\mathrm{~B}_{\mathrm{d}_{s a}}^{2}} \int_{-\infty}^{+\infty} \int_{-1}^{0} \overline{\mathrm{s}}_{\mathrm{d}} \mathrm{dx}_{\mathrm{d}} \mathrm{dy}_{\mathrm{d}}=\overline{\mathrm{Q}}_{\mathrm{zd}_{\mathrm{nif}} \mathrm{BZT}_{\mathrm{BT}}}
$$

which, as shown, is exactly the expression for total leakage (stream depletion) in an aquifer of infinite length (equation (6)).

[18] The above proof can be readily extended to show that the same agreement is obtained for the case of boundaries in both the positive and negative y directions. Thus stream-depletion plots for an aquifer of infinite length can be used to calculate stream depletion in a bounded aquifer of any length. This scale invariance should be of considerable interest to water managers and water-right adjudicators working in interconnected streamaquifer systems, as an impermeable boundary (e.g., a dam or mountain front) will not affect stream-depletion calculations as long as the stream and aquifer remain in hydraulic connection.

[19] The scale invariance of total leakage is not restricted to pumping-induced stream depletion. Consider the case of a rectangular semiconfined aquifer in which leakage can be represented by the Hantush-Jacob model and that is bounded on all sides by impermeable formations. In this situation, total leakage is most easily calculated using a numerical model. Figures $6 \mathrm{a}$ and $6 \mathrm{~b}$ are plots of drawdown and total leakage, respectively, versus dimensionless time for a series of rectangular aquifers that vary in size by six orders of magnitude. Although drawdown varies with the size of the aquifer (Figure 6a), total leakage does not (Figure 6b). In all cases, the total leakage is the same as that for an aquifer of infinite lateral extent (equation (3)), despite the differences in drawdown.

[20] Image well theory can again be used to prove the universality of this scale invariance. Figure 7 illustrates a portion of the infinite network of image wells that would arise for a rectangular aquifer bounded on all sides by impermeable formations. The total leakage is the summation of the leakage produced by each well, which is calculated by integrating the analytical expression for leakage (equation (2)) over the finite aquifer. In this case, the contribution of each well is calculated using the Cartesian coordinate form of equation (2). The component of leakage produced by the actual pumping well in Figure 7 is

$$
\overline{\mathrm{Q}}_{\mathrm{zd}_{\mathrm{A} 1}}=\frac{1}{\mathrm{~B}_{\mathrm{d}}^{2}} \int_{-\mathrm{y}_{\mathrm{d} 1}}^{\mathrm{y}_{\mathrm{d} 2}} \int_{-\mathrm{x}_{\mathrm{d} 1}}^{\mathrm{x}_{\mathrm{d} 2}} \overline{\mathrm{s}}_{\mathrm{d}} \mathrm{dx}_{\mathrm{d}} \mathrm{dy}_{\mathrm{d}}
$$

where $\mathrm{x}_{\mathrm{di}}\left(=\mathrm{x}_{\mathrm{i}} / \mathrm{b}\right)$ and $\mathrm{y}_{\mathrm{di}}\left(=\mathrm{y}_{\mathrm{i}} / \mathrm{b}\right)$ are normalized distances in the $\mathrm{x}$ and $\mathrm{y}$ directions, respectively. The component of leakage produced by the two closest image wells in the center row on Figure 7 is

$$
\overline{\mathrm{Q}}_{\mathrm{zd} \mathrm{d} 2}=\frac{1}{\mathrm{~B}_{\mathrm{d}}^{2}} \int_{-\mathrm{y}_{\mathrm{d} 1}}^{\mathrm{y}_{\mathrm{d} 2}} \int_{-\mathrm{x}_{\mathrm{d} 1}-\Delta \mathrm{x}_{\mathrm{d}}}^{-\mathrm{x}_{\mathrm{d} 1}} \overline{\mathrm{s}}_{\mathrm{d}} \mathrm{dx}_{\mathrm{d}} \mathrm{d} \mathrm{y}_{\mathrm{d}}+\frac{1}{\mathrm{~B}_{\mathrm{d}}^{2}} \int_{-\mathrm{y}_{\mathrm{d} 1}}^{\mathrm{y}_{\mathrm{d} 2}} \int_{\mathrm{x}_{\mathrm{d} 2}}^{\mathrm{x}_{\mathrm{d} 2}+\Delta \mathrm{x}_{\mathrm{d}}} \overline{\mathrm{s}}_{\mathrm{d}} \mathrm{dx}_{\mathrm{d}} \mathrm{d} \mathrm{y}_{\mathrm{d}}
$$

where $\Delta \mathrm{x}_{\mathrm{d}}$ is the dimensionless width of the aquifer $\left(\mathrm{x}_{\mathrm{d} 2}+\mathrm{x}_{\mathrm{d} 1}\right)$, and the origin of the coordinate system for each double integral is at the respective image well. The first double integral is the contribution of the closest image well from the group denoted series 1 on Figure 7, while the second double integral is the contribution of the closest 

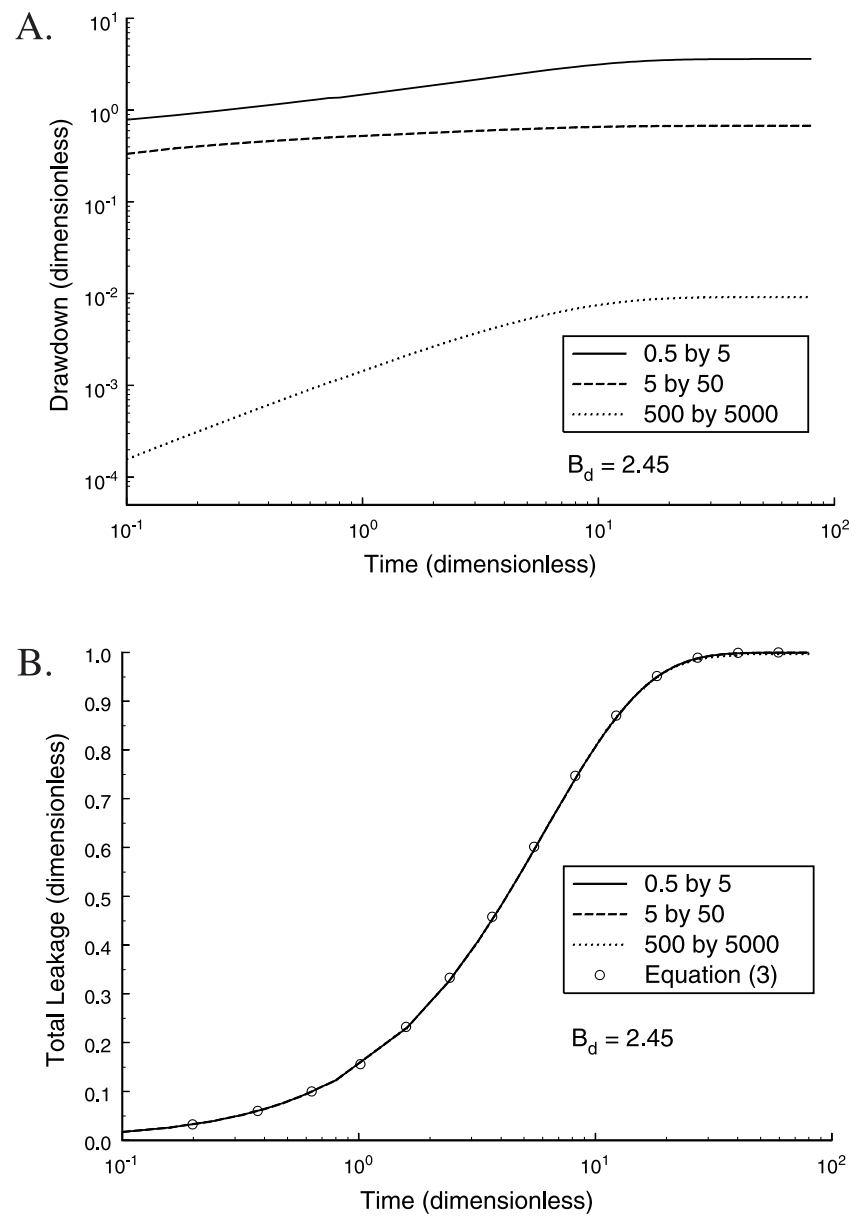

Figure 6. (a) Dimensionless drawdown $(2 \pi s \mathrm{~T} / \mathrm{Q})$ at the pumping well versus dimensionless time $\left(\mathrm{Tt} / \mathrm{Sb}^{2}\right)$ plot for rectangular aquifers bounded by impermeable formations. (b) Dimensionless total leakage $\left(\mathrm{Q}_{\mathrm{z}} / \mathrm{Q}\right)$ versus dimensionless time plot for the same aquifers (dimensionless aquifer widths and lengths defined in legend; curves for rectangular aquifers generated with MODFLOW [Harbaugh and McDonald, 1996] using the same number of grid cells in all simulations with the pumping well at the center of the aquifer).

image well from the group denoted series 2 on Figure 7. The component of leakage produced by all wells in the center row of Figure 7 is

$$
\begin{gathered}
\overline{\mathrm{Q}}_{\mathrm{zd}_{\mathrm{A}}}=\frac{1}{\mathrm{~B}_{\mathrm{d}}^{2}} \int_{-\mathrm{y}_{\mathrm{d} 1}}^{\mathrm{y}_{\mathrm{d} 2}} \int_{-\mathrm{x}_{\mathrm{d} 1}}^{\mathrm{x}_{\mathrm{d} 2}} \overline{\mathrm{s}}_{\mathrm{d}} \mathrm{dx}_{\mathrm{d}} \mathrm{dy} \mathrm{y}_{\mathrm{d}}+\frac{1}{\mathrm{~B}_{\mathrm{d}}^{2}} \sum_{\mathrm{j}=1}^{\infty}\left(\int_{-\mathrm{y}_{\mathrm{d} 1}}^{\mathrm{y}_{\mathrm{d} 2}} \int_{-\mathrm{x}_{\mathrm{d} 1}-\mathrm{j} \Delta \mathrm{x}_{\mathrm{d}}}^{-\mathrm{x}_{\mathrm{d} 1}-(\mathrm{j}-1) \Delta \mathrm{x}_{\mathrm{d}}}\right. \\
\left.\cdot \overline{\mathrm{s}}_{\mathrm{d}} \mathrm{dx}_{\mathrm{d}} \mathrm{dy} \mathrm{y}_{\mathrm{d}}+\int_{-\mathrm{y}_{\mathrm{d} 1}}^{\mathrm{y}_{\mathrm{d} 2}} \int_{\mathrm{x}_{\mathrm{d} 2}+(\mathrm{j}-1) \Delta \mathrm{x}_{\mathrm{d}}}^{\mathrm{x}_{\mathrm{d} 2}+\mathrm{j} \Delta \mathrm{x}_{\mathrm{d}}} \overline{\mathrm{s}}_{\mathrm{d}} \mathrm{dx}_{\mathrm{d}} \mathrm{dy} \mathrm{y}_{\mathrm{d}}\right) \\
\overline{\mathrm{Q}}_{\mathrm{zd}_{\mathrm{A}}}=\frac{1}{\mathrm{~B}_{\mathrm{d}}^{2}} \int_{-\mathrm{y}_{\mathrm{d} 1}}^{\mathrm{y}_{\mathrm{d} 2}} \int_{-\infty}^{+\infty} \overline{\mathrm{s}}_{\mathrm{d}} \mathrm{dx}_{\mathrm{d}} \mathrm{dy} \mathrm{y}_{\mathrm{d}}
\end{gathered}
$$

where the first term in the summation of equation (8c) is the contribution of the series 1 image wells, and the second term is the contribution of the series 2 image wells.

[21] Summation over all rows of image wells yields

$$
\begin{aligned}
& \overline{\mathrm{Q}}_{\mathrm{zd}}=\frac{1}{\mathrm{~B}_{\mathrm{d}}^{2}} \int_{-\mathrm{x}_{\mathrm{d} 1}}^{\mathrm{x}_{\mathrm{d} 2}} \int_{-\mathrm{y}_{\mathrm{d} 1}}^{\mathrm{y}_{\mathrm{d} 2}} \overline{\mathrm{s}}_{\mathrm{d}} \mathrm{dy}_{\mathrm{d}} \mathrm{dx}_{\mathrm{d}}+\frac{1}{\mathrm{~B}_{\mathrm{d}}^{2}} \sum_{\mathrm{j}=0}^{\infty} \sum_{\mathrm{i}=1}^{\infty} \\
& \left(\int_{-y_{\mathrm{d} 1}-\mathrm{j} \Delta \mathrm{y}_{\mathrm{d}}}^{-\mathrm{y}_{\mathrm{d} 1}-(\mathrm{j}-1) \Delta \mathrm{y}_{\mathrm{d}}} \int_{-\mathrm{x}_{\mathrm{d} 1}-\mathrm{i} \Delta \mathrm{x}_{\mathrm{d}}}^{-\mathrm{x}_{\mathrm{d} 1}-(\mathrm{i}-1) \Delta \mathrm{x}_{\mathrm{d}}} \overline{\mathrm{s}}_{\mathrm{d}} \mathrm{dx}_{\mathrm{d}} \mathrm{d} \mathrm{y}_{\mathrm{d}}\right. \\
& +\int_{-\mathrm{y}_{\mathrm{d} 1}-\mathrm{j} \Delta \mathrm{y}_{\mathrm{d}}}^{-\mathrm{y}_{\mathrm{d} 1}-(\mathrm{j}-1) \Delta \mathrm{y}_{\mathrm{d}}} \int_{\mathrm{x}_{\mathrm{d} 2}+(\mathrm{i}-1) \Delta \mathrm{x}_{\mathrm{d}}}^{\mathrm{x}_{\mathrm{d} 2}+\mathrm{i} \Delta \mathrm{x}_{\mathrm{d}}} \overline{\mathrm{s}}_{\mathrm{d}} \mathrm{dx} \mathrm{d}_{\mathrm{d}} \mathrm{dy} \text { d } \\
& +\frac{1}{B_{d}^{2}} \sum_{j=1}^{\infty} \sum_{i=1}^{\infty}\left(\int_{y_{d 2}+(j-1) \Delta y_{d}}^{y_{d}+j \Delta y_{d}} \int_{-x_{d 1}-i \Delta x_{d}}^{-x_{d}-(i-1) \Delta x_{d}} \bar{s}_{d} \mathrm{dx}_{d} d y_{d}\right. \\
& \left.+\int_{\mathrm{y}_{\mathrm{d} 2}+(\mathrm{j}-1) \Delta \mathrm{y}_{\mathrm{d}}}^{\mathrm{y}_{\mathrm{d} 2}+\mathrm{j} \Delta \mathrm{y}_{\mathrm{d}}} \int_{\mathrm{x}_{\mathrm{d} 2}+(\mathrm{i}-1) \Delta \mathrm{x}_{\mathrm{d}}}^{\mathrm{x}_{\mathrm{d} 2}+\mathrm{i} \Delta \mathrm{x}_{\mathrm{d}}} \overline{\mathrm{s}}_{\mathrm{d}} \mathrm{dx}_{\mathrm{d}} \mathrm{dy} \mathrm{y}_{\mathrm{d}}\right) \\
& +\frac{1}{B_{d}^{2}} \sum_{j=1}^{\infty}\left(\int_{-x_{d 1}}^{x_{d} 2} \int_{-y_{d 1}-j \Delta y_{d}}^{-y_{d 1}-(j-1) \Delta y_{d}} \bar{s}_{d} d_{d} d x_{d}\right. \\
& \left.+\int_{-\mathrm{x}_{\mathrm{d} 1}}^{\mathrm{x}_{\mathrm{d} 2}} \int_{\mathrm{y}_{\mathrm{d} 2}+(\mathrm{j}-1) \Delta \mathrm{y}_{\mathrm{d}}}^{\mathrm{y}_{\mathrm{d} 2}+\mathrm{j} \Delta \mathrm{y}_{\mathrm{d}}} \overline{\mathrm{s}}_{\mathrm{d}} \mathrm{dy}_{\mathrm{d}} \mathrm{dx}_{\mathrm{d}}\right)
\end{aligned}
$$

where $\Delta \mathrm{y}_{\mathrm{d}}$ is the dimensionless length of the aquifer $\left(\mathrm{y}_{\mathrm{d} 2}+\right.$ $\left.\mathrm{y}_{\mathrm{d} 1}\right)$, the first term is the component of leakage produced by the actual pumping well, the first double summation is the contribution of series 1 and 2 image wells in the center row and the negative $y$ direction, the second double summation is the contribution of series 1 and 2 image wells in the positive $y$ direction, and the final summation is the contribution of series 3 and 4 image wells. In all cases, the contribution of each image well is computed assuming that the origin of the coordinate system is at the location of that image well.

[22] Consideration of the contribution of all the wells in equation (9) allows the equation to be rewritten in a concise form as

$$
\overline{\mathrm{Q}}_{\mathrm{zd}}=\frac{1}{\mathrm{~B}_{\mathrm{d}}^{2}} \int_{-\infty}^{+\infty} \int_{-\infty}^{+\infty} \overline{\mathrm{s}}_{\mathrm{d}} \mathrm{dy}_{\mathrm{d}} \mathrm{dx} \mathrm{x}_{\mathrm{d}}=\overline{\mathrm{Q}}_{\mathrm{zd}_{\mathrm{inf}_{\mathrm{HJ}}}}
$$

which, as shown, is exactly equal to the Cartesian coordinate form of equation (3). Equation (10) therefore demonstrates that the total leakage for a bounded rectangular aquifer is the same as that for an aquifer of infinite lateral extent. Thus, regardless of the size of the aquifer or the distance from the pumping well to a no-flow boundary, the total leakage is the same as in the case of a laterally infinite system. Although this proof utilized the HantushJacob conceptualization of a semiconfined aquifer, the same result could be obtained using other conceptualizations [e.g., Hantush, 1960; Neuman and Witherspoon, 1969].

[23] The above proof was based on a simple rectangular aquifer because that geometry could be readily represented 


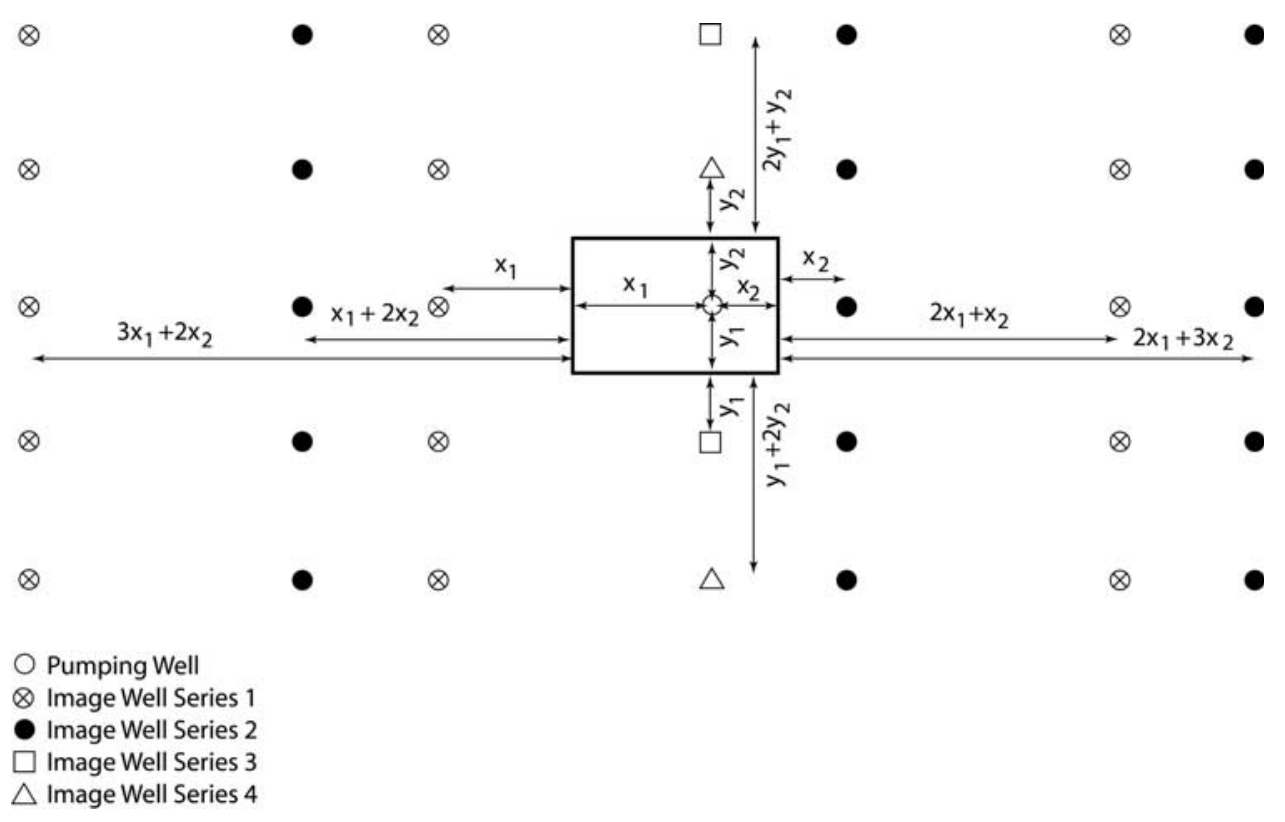

Figure 7. Image well representation of rectangular aquifer bounded by impermeable formations on all sides (near-aquifer image wells are shown from a network that extends to infinity in all directions). Series 1 image wells are image wells related to the image well at a distance of $\mathrm{x}_{1}$ from the left boundary of the aquifer. Series 2 image wells are image wells related to the image well at a distance of $x_{2}$ from the right boundary of the aquifer. Series 3 image wells are image wells related to the image well at a distance of $y_{1}$ from the lower boundary of the aquifer. Series 4 image wells are image wells related to the image well at a distance of $y_{2}$ from the upper boundary of the aquifer. Image wells not on the axes centered on the actual pumping well are shown as series 1 or series 2 to allow a more straightforward derivation in text.

using image wells. A similar image well proof, albeit more involved, could be developed to show this scale invariance for a wide range of more complicated aquifer geometries (see Streltsova [1988] for a discussion of use of image wells to represent aquifer boundaries intersecting at an arbitrary angle). A completely general proof, however, has yet to be obtained.

[24] The scale invariance of total leakage is not an intuitively obvious phenomenon. As the areal extent of an aquifer that is laterally bounded by impermeable formations decreases, drawdown and the leakage per unit area clearly must increase. What is not as clear, however, is that the relationship between drawdown and leakage is such that the integral of leakage over the aquifer (total leakage) remains the same, regardless of the size of the aquifer. Note that this scale invariance of total leakage is accompanied by a scale invariance in the time to steady state (Figures 5a and 6a) and in the integral of drawdown over the aquifer (equations (3)(4) and (6)). These additional scale-invariant phenomena also have considerable practical significance.

\section{Conclusions}

[25] The quantification of the volume of pumpinginduced leakage entering an aquifer as a function of time is necessary for a wide range of practical applications. In this study a new approach for calculation of this total leakage was developed for aquifers that are laterally bounded by impermeable formations. This approach is based on a simplification that allows estimates of total leakage calculated for aquifers of infinite extent to be used for aquifers of any size. The practical ramifications are significant, as the total leakage for an infinite aquifer can be readily calculated and presented in a type-curve format.

[26] The simplification upon which the new approach is based is possible because of the relationship between drawdown and leakage in aquifers bounded by impermeable formations. This relationship produces a condition in which the total leakage does not change as a function of the size of the aquifer or the proximity of the pumping well to an impermeable boundary. Image well theory was used here to prove the generality of this interesting phenomenon.

[27] Acknowledgments. This manuscript benefited from reviews provided by Geoff Bohling, Xiaoyong Zhan, Li Zheng, and two anonymous reviewers.

\section{References}

Anderson, M. P., and W. W. Woessner, Applied Groundwater Modeling, 381 pp., Academic, San Diego, Calif., 1992.

Butler, J. J., Jr., Mathematical derivations of expressions for the total pumping-induced leakage entering an aquifer, Kans. Geol. Surv. Open File Rep., 2003-6, 13 pp., 2003. (Available at www.kgs.ku.edu/StreamAq/ index.html)

Butler, J. J., Jr., V. A. Zlotnik, and M.-S. Tsou, Drawdown and stream depletion produced by pumping in the vicinity of a partially penetrating stream, Ground Water, 39(5), 651-659, 2001.

Ferris, J. G., D. B. Knowles, R. H. Brown, and R. W. Stallman, Theory of aquifer tests, U.S. Geol. Surv. Water Supply Pap., 1536-E, 174 pp., 1962.

Hantush, M. S., Modification of the theory of leaky aquifers, J. Geophys. Res., 65(11), 3713-3725, 1960.

Hantush, M. S., and C. E. Jacob, Non-steady radial flow in an infinite leaky aquifer, Eos Trans. AGU, 36(1), 95-100, 1955.

Harbaugh, A. W., and J. M. McDonald, User's documentation for MODFLOW-96, an update to the U.S. Geological Survey modular 
finite-difference ground-water flow model, U.S. Geol. Surv. Open File Rep., 96-485, 1996.

Moench, A., and A. Ogata, Analysis of constant discharge wells by numerical inversion of Laplace transform solutions, in Groundwater Hydraulics, Water Resour. Monogr., vol. 9, edited by J. Rosenshein and G. D. Bennett, pp. 146-170, AGU, Washington, D. C., 1984.

Neuman, S. P., and P. A. Witherspoon, Theory of flow in a confined two aquifer system, Water Resour. Res., 5(4), 803-816, 1969.

Stehfest, H., Numerical inversion of Laplace transforms, Commun. ACM, 13(1), 47-49, 1970
Streltsova, T. D., Well Testing in Heterogeneous Formations, 413 pp., John Wiley, Hoboken, N. J., 1988.

J. J. Butler Jr., Kansas Geological Survey, 1930 Constant Avenue, Campus West, University of Kansas, Lawrence, KS 66047, USA. (jbutler@ kgs.ku.edu)

M.-S. Tsou, HydroGeoLogic, Inc., 12343 Hymeadow Drive, Suite 3B, Austin, TX 78750, USA. 